\title{
HFC-23 $\left(\mathrm{CHF}_{3}\right)$ emission trend response to $\mathrm{HCFC}-22\left(\mathrm{CHClF}_{2}\right)$ production and recent $\mathrm{HFC}-23$ emission abatement measures
}

\author{
B. R. Miller ${ }^{1,2}$, M. Rigby ${ }^{3}$, L. J. M. Kuijpers ${ }^{4}$, P. B. Krummel ${ }^{5}$, L. P. Steele ${ }^{5}$, M. Leist ${ }^{5}$, P. J. Fraser ${ }^{5}$, A. McCulloch ${ }^{6}$, \\ C. Harth $^{2}$, P. Salameh ${ }^{2}$, J. Mühle ${ }^{2}$, R. F. Weiss ${ }^{2}$, R. G. Prinn ${ }^{3}$, R. H. J. Wang ${ }^{7}$, S. O'Doherty ${ }^{6}$, B. R. Greally ${ }^{6}$, and \\ P. G. Simmonds ${ }^{6}$ \\ ${ }^{1}$ Cooperative Institute for Research in Environmental Sciences, University of Colorado, Boulder, Colorado, USA \\ ${ }^{2}$ Scripps Institution of Oceanography, University of California, San Diego, La Jolla, California, USA \\ ${ }^{3}$ Center for Global Change Science, Massachusetts Institute of Technology, Cambridge, Massachusetts, USA \\ ${ }^{4}$ Eindhoven Centre for Sustainability, Technical University Eindhoven, Eindhoven, The Netherlands \\ ${ }^{5}$ Centre for Australian Weather and Climate Research, CSIRO Marine and Atmospheric Research, Aspendale, \\ Victoria, Australia \\ ${ }^{6}$ School of Chemistry, University of Bristol, Bristol, UK \\ ${ }^{7}$ School of Earth and Atmospheric Sciences, Georgia Institute of Technology, Atlanta, Georgia, USA
}

Received: 13 April 2010 - Published in Atmos. Chem. Phys. Discuss.: 25 May 2010

Revised: 23 July 2010 - Accepted: 13 August 2010 - Published: 25 August 2010

\begin{abstract}
HFC-23 (also known as $\mathrm{CHF}_{3}$, fluoroform or trifluoromethane) is a potent greenhouse gas (GHG), with a global warming potential (GWP) of 14800 for a 100-year time horizon. It is an unavoidable by-product of HCFC$22\left(\mathrm{CHClF}_{2}\right.$, chlorodifluoromethane) production. HCFC22, an ozone depleting substance (ODS), is used extensively in commercial refrigeration and air conditioning, in the extruded polystyrene (XPS) foam industries (dispersive applications) and also as a feedstock in fluoropolymer manufacture (a non-dispersive use). Aside from small markets in specialty uses, HFC-23 has historically been considered a waste gas that was, and often still is, simply vented to the atmosphere. Efforts have been made in the past two decades to reduce HFC-23 emissions, including destruction (incineration) in facilities in developing countries under the United Nations Framework Convention on Climate Change's (UNFCCC) Clean Development Mechanism (CDM), and by process optimization and/or voluntary incineration by most producers in developed countries.

We present observations of lower-tropospheric mole fractions of HFC-23 measured by "Medusa" GC/MSD instruments from ambient air sampled in situ at the Advanced Global Atmospheric Gases Experiment (AGAGE) network of five remote sites (2007-2009) and in Cape
\end{abstract}

Correspondence to: B. R. Miller

(ben.r.miller@noaa.gov)
Grim air archive (CGAA) samples (1978-2009) from Tasmania, Australia. These observations are used with the AGAGE 2-D atmospheric 12-box model and an inverse method to produce model mole fractions and a "top-down" HFC-23 emission history. The model 2009 annual mean global lower-tropospheric background abundance is 22.6 $( \pm 0.2) \mathrm{pmol} \mathrm{mol}^{-1}$. The derived HFC-23 emissions show a "plateau" during 1997-2003, followed by a rapid $~ 50 \%$ increase to a peak of $15.0(+1.3 /-1.2) \mathrm{Gg} / \mathrm{yr}$ in 2006. Following this peak, emissions of HFC-23 declined rapidly to 8.6 $(+0.9 /-1.0) \mathrm{Gg} / \mathrm{yr}$ in 2009 , the lowest annual emission of the past 15 years.

We derive a 1990-2008 "bottom-up" HFC-23 emission history using data from the United Nations Environment Programme and the UNFCCC. Comparison with the top-down HFC-23 emission history shows agreement within the stated uncertainties. In the 1990s, HFC-23 emissions from developed countries dominated all other sources, then began to decline and eventually became fairly constant during 20032008. By this point, with developed countries' emissions essentially at a plateau, the major factor controlling the annual dynamics of global HFC-23 emissions became the historical rise of developing countries' HCFC-22 dispersive use production, which peaked in 2007 . Thereafter in 2007 2009, incineration through CDM projects became a larger factor, reducing global HFC-23 emissions despite rapidly rising HCFC-22 feedstock production in developing countries. 


\section{Introduction}

HFC-23 $\left(\mathrm{CHF}_{3}\right)$ is a potent greenhouse gas with a global warming potential (GWP) of 14800 for a 100 -year time horizon, (Forster and Ramaswamy, 2007). HFC-23 is a relatively long-lived trace gas with a tropospheric lifetime of 260-270 years (Naik et al., 2000; Forster and Ramaswamy, 2007). HFC-23 is an unavoidable by-product of HCFC-22 $\left(\mathrm{CHClF}_{2}\right.$, chlorodifluoromethane) production. HCFC-22 is used extensively in the commercial refrigeration, air conditioning and extruded polystyrene (XPS) foam industries, as well as in other minor uses, all of which result in emissions to the atmosphere. HCFC-22 is also used as a feedstock in fluoropolymer manufacture, which is considered a non-dispersive use. HCFC-22 has an ozone depletion potential (ODP) of 0.055 (Daniel et al., 2007). Montzka et al. (2009) reported accelerated growth in the atmospheric abundance of HCFC-22 during 2006-2007, relative to that of 2003-2004. This growth coincided with exponential growth in developing countries' production and consumption of the three most abundant HCFCs. HCFC-22 is included in the phase-out of HCFC consumption and production for dispersive uses in developed countries under the Montreal Protocol and its amendments (UNEP, 1996). Decision XIX/6 of the 2007 Meeting of the Montreal Protocol Parties stipulates an accelerated phase-out time table for production and consumption of HCFCs for dispersive applications in developed and developing countries (UNEP, 2007). Developing countries will be subject to a phase-out beginning with a freeze in 2013, with the baseline for that phase-out based on the average ODP-weighted production and consumption of 2009 and 2010. The production of HCFC-22 for use as feedstock, however, is unrestricted. These two latter aspects of HCFC22 production regulation have implications for the future production of the by-product HFC-23, as we shall see.

In contrast to the widespread industrial uses of HCFC22, HFC-23 has limited industrial uses. These include use as feedstock in Halon-1301 $\left(\mathrm{CBrF}_{3}\right)$ production (nondispersive), in semiconductor fabrication (mostly nondispersive), in very low temperature (VLT) refrigeration (dispersive) and in specialty fire suppressant systems (dispersive) (McCulloch and Lindley, 2007; Barthos et al., 2006; DuPont, 2004). Thus the bulk of the co-produced HFC-23 was historically considered a waste gas that has been and often continues to be vented to the atmosphere. Since the 1990s, some HCFC-22 producers in the developed countries have voluntarily reduced HFC-23 emissions by process optimization and/or incineration. Based on historical trends, McCulloch (2004) concluded that "approximately half of the HFC-23 co-produced with HCFC-22 in the developed world is abated." Under the Clean Development Mechanism (CDM) of the United Nations Framework Convention on Climate Change (UNFCCC) 19 HCFC-22 production plants in five developing countries were approved for participation as CDM projects. These countries have reportedly incinerated the HFC-23 co-produced during 2007-2008 from 43-48\% of the developing world's HCFC-22 production (Montzka et al., 2010).

Typical HFC-23/HCFC-22 co-production ratios, often referred to as the waste gas generation ratio " $w$ ", range from 0.014 in optimized processes (Rotherham, 2004) to upwards of $\sim 0.04$ (McCulloch and Lindley, 2007). This coproduction relationship of HFC-23 and HCFC-22 provides a unique constraint in evaluating their emission and production trends as HFC-23 may act as a tracer of HCFC-22 production while the fate of HCFC-22 involves a more convoluted path of various end-uses and different release rates. To the extent that HCFC-22 production, waste gas generation ratio and HFC-23 incineration are known, a bottom-up emission history for HFC-23 can be derived, as we will show for developing countries later in this paper.

In the sections that follow, we present observations of lower-tropospheric mole fractions of HFC-23 measured by "Medusa" gas chromatography/mass spectrometric detection (GC/MSD) instruments from ambient air sampled in situ at the Advanced Global Atmospheric Gases Experiment (AGAGE) network of five remote sites (2007-2009) and in Cape Grim air archive (CGAA) samples (1978-2009) from Tasmania, Australia. These observations are used in a Kalman filter inversion with the AGAGE 2-D atmospheric 12-box model to produce an emission history for HFC-23. We also discuss production and emission data reported to the United Nations and other organizations, and use these data to construct an emission history for use as an "a priori" estimate for the inversion in the 2-D model. A segment (19902008) of this a priori emission history will later be compared as a "bottom-up" history to the model optimized (top-down) emission history. This comparison will allow a quantitative examination of the impact of developed countries' emissions, developing countries' HCFC-22 production for both dispersive and feedstock uses, and recent HFC-23 emission abatement measures via the CDM projects on the trend in global HFC-23 emissions.

The first published time series of the atmospheric abundance of HFC-23 was given by Oram et al. (1998) and was based on analyses by GC/MSD of subsamples of archived air from the Southern Hemisphere. They compared these observations with abundances derived from a 2-D global model to estimate global emissions of HFC-23. Subsequently, Culbertson et al. (2004) published a Northern Hemisphere time series based on GC/MSD analysis of archived air samples, and used a one-box model to estimate global emissions of HFC-23. Most recently, Montzka et al. (2010) used GC/MSD analyses of Antarctic firn air and surface samples to estimate global emissions of HFC-23. The relationships between these previously published emission estimates and those derived in this paper are described in the Results section. The present paper extends HFC-23 atmospheric observations through 2009 and, in combination with an independent bottom-up analysis, improves upon the two latter studies 
Table 1. Analytical instruments, locations and samples used in this study.

\begin{tabular}{lll}
\hline Instrument & Location & Samples and date range \\
\hline Medusa1 GC/MSD & La Jolla (SIO), California, USA $\left(33^{\circ} \mathrm{N}, 117^{\circ} \mathrm{W}\right)$ & $\begin{array}{l}\text { Central instrument for absolute calibrations } \\
\text { 2003 to Dec. 2009 }\end{array}$ \\
Medusa2 GC/MSD & Mace Head (MHD), Ireland $\left(53^{\circ} \mathrm{N}, 10^{\circ} \mathrm{W}\right)$ & In situ Oct. 2007-Dec. 2009 \\
Medusa3 GC/MSD & Cape Grim (CGO), Tasmania, Australia, $\left(41^{\circ} \mathrm{S}, 145^{\circ} \mathrm{E}\right)$ & $\begin{array}{l}\text { In situ Nov. } 2007-D e c . ~ 2009 ; \\
\text { archive }(1990-2009)\end{array}$ \\
& & In situ Sep. 2007-Dec. 2009 \\
Medusa4 GC/MSD & Trinidad Head (THD), California, USA $\left(41^{\circ} \mathrm{N}, 124^{\circ} \mathrm{W}\right)$ & In situ Aug. 2007-Dec. 2009 \\
Medusa5 GC/MSD & Ragged Point (RPB), Barbados $\left(13^{\circ} \mathrm{N}, 59^{\circ} \mathrm{W}\right)$ & In situ Oct. 2007-Sep. 2009 \\
Medusa6 GC/MSD & Cape Matatula (SMO), American Samoa, USA $\left(14^{\circ} \mathrm{S}, 171^{\circ} \mathrm{W}\right)$ & CGAA archive (1978-2006) \\
\hline
\end{tabular}

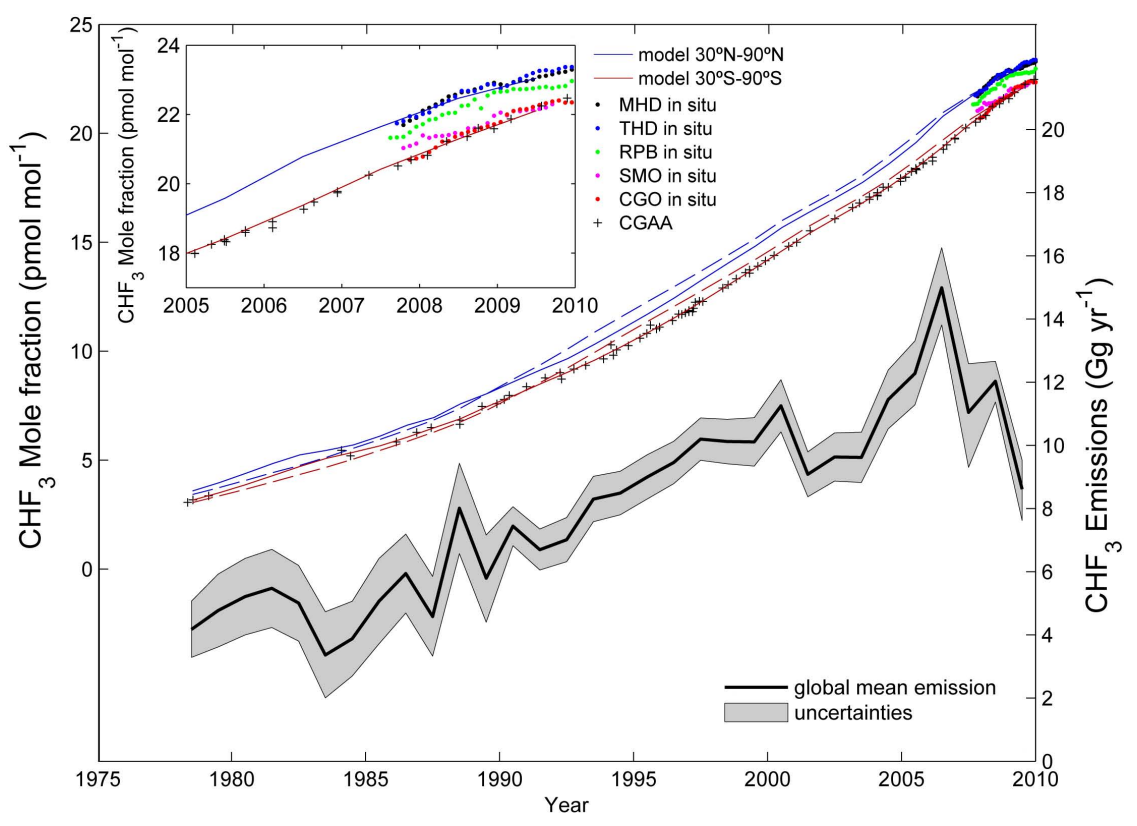

Fig. 1. Atmospheric HFC-23 $\left(\mathrm{CHF}_{3}\right)$ mole fractions (left axis and inset) based on the monthly means of AGAGE "Medusa" GC/MSD in situ measurements at 5 remote sites and from Cape Grim air archive (CGAA) samples. Model optimized annual mean mole fractions (solid lines) from inversion using the 2-D 12-box model are shown for the high latitude northern and southern semi-hemisphere boxes. Model annual mean a priori mole fractions are also shown (dashed lines) to illustrate that the a priori emission estimate produces mole fraction growth rates that generally agree with the observations. The HFC-23 global emission estimate from the inversion is shown along with uncertainties (right axis). The atmospheric trend shows deceleration in growth since 2006 that is reflected in a maximum emission of 15.0 $(+1.3 /-1.2)$ Gg HFC-23 in 2006, followed by decreasing emissions over the subsequent three years to a low of $8.6(+0.9 /-1.0) \mathrm{Gg}$, which is the lowest emission of the past 15 years.

by providing the temporal resolution that resolves several policy-relevant issues regarding source strength attribution and/or the efficacy of recent abatement measures, and additionally provides a foundation for anticipating future emission trends.

Note, in the discussion that follows, we use the terms "developed countries" and "developing countries" to mean Annex 1 and Non-Annex 1 countries under the Kyoto Protocol, respectively, and to mean Non-Article 5 and Article 5 countries under the Montreal Protocol, respectively. Note also that all data are plotted and tabulated as annual mean midyear values.

\section{Analytical studies}

Figure 1 introduces the observational dataset for HFC-23, showing the in situ measurements along with the results of CGAA analyses. The emission results of the inverse modeling are also shown in this figure. A striking feature of this plot is the recent rapid decline in atmospheric emissions, 
which is caused by recent emission abatement measures in the developing world as discussed in section 6 , and the corresponding recent slow down in atmospheric mole fraction growth.

Analyses for HFC-23 were performed in situ at remote locations around the globe and on CGAA whole air samples using the AGAGE Medusa GC/MSD (Miller et al., 2008). The various instruments, their locations, the sample types analyzed and the date ranges of the samples used in this study are listed in Table 1.

Measurements for all CGAA and in situ analyses are referenced to a common relative scale, the SIO R1 scale, which is based on traceable comparisons of a hierarchy of whole real air samples to a specific archived 2003 air sample denoted "R1" from Trinidad Head, California. All results are assigned absolute calibration based on the assigned value of R1 and are presented here as dry-gas mole fractions in pmol mol${ }^{-1}$ (equivalent to parts-per-trillion molar, ppt) on the SIO-2007 absolute calibration scale (Miller, 1998) for HFC-23. The absolute accuracy of this gravimetricbased calibration scale, as generally described by Prinn et al. (2000), is estimated as $+2 \% /-3 \%$ with the asymmetry arising from the fact that the purity of the HFC-23 reagent used in the primary standard preparations was specified as $>99 \%$.

Medusa utilizes analyte preconcentration on adsorbents at low temperature to enhance signal-to-noise ratios. Medusa in situ analyses involve 2-L samples drawn from a nearby tower and integrated over 20-min collection times. Sampling of ambient air is typically performed once every two hours with reference gas analyses of the same volume of compressed whole air ("quaternary standards") in between each ambient air measurement to track sensitivity and to produce $\sim 12$ calibrated ambient air measurements per day. Although the in situ HFC-23 records are relatively short (late 2007 to end of 2009), together they comprise more than 34,000 baseline ambient air analyses. MSD response to HFC-23 in samples was quantified using target mass over charge $(\mathrm{m} / \mathrm{z})$ ratio 51 , which is the second most abundant ion in the mass spectrum of HFC-23. This ion fragment is not in common with PFC$116\left(\mathrm{C}_{2} \mathrm{~F}_{6}\right)$, which nearly co-elutes with HFC-23 on the separation column. The response of ion $m / z 69$, which is common to both PFC-116 and HFC-23, was also monitored as a qualifier ion to aid in identifying this and other potential chromatographic separation interferences. Medusa calibration of quaternary standards is performed by on-site comparison with contemporary compressed whole air "tertiary" references that are exchanged between the field site and the central calibration laboratory at Scripps Institution of Oceanography, La Jolla, California.

Data processing of the Cape Grim air archive analyses using Medusa9 (Aspendale, Victoria) allows for determination and, if necessary, correction of instrument non-linearities and system blank contamination. While no system blank contamination was discernible for Medusa9, a contamination equiv- alent to $<1 \%$ of ambient HFC-23 mole fractions was noted in the Medusa4 instrument at Trinidad Head during 20082009. A composite determination of the instrument response for HFC-23, based on data acquired before, during and after the Medusa9 analyses of the CGAA samples is shown in Fig. S1 in the supplementary materials, indicating that the response is linear over a range greater than the mole fraction range of the CGAA samples. This performance characterization is essential to ensure that reliable sensitivities are applied to the wide range of atmospheric mole fractions that span over a factor of six. For the in situ data, non-linearity is less of a concern due to the use of contemporary ambient air reference gases that closely match the mole fractions observed at the stations.

The CGAA are samples of clean background "baseline" air that have been collected at the Cape Grim Baseline Air Pollution Station on the west coast of Tasmania since 1978. The extant CGAA subset of 82 archive samples spanning 1978 to 2009 was analyzed for this study. All samples were whole air pressurized by cryogenic trapping and archived in 35-L electropolished stainless steel cylinders or in aluminum cylinders in which the internal surfaces had been passivated by a proprietary process believed to be based upon the use of substituted silane gases. Most of these samples were trapped as whole moist air, with most of the condensed liquid water being expelled after trapping, but the samples trapped in aluminum cylinders were dried cryogenically or chemically before trapping to avoid degradation of the passivated surfaces. A more complete description of the methods used, and the philosophy underpinning this air archive, is given by Langenfelds et al. (1996).

A brief discussion of CGAA sampling artifacts and storage stability is warranted to lend confidence to the resultant atmospheric history that spans 31 years and is based on analyses that occurred up to 28 years after sampling. As is evident in Fig. 1, the CGAA data for HFC-23 merge seamlessly with the Cape Grim (CGO) in situ high frequency data, indicating no discernible sampling artifacts or shortterm storage degradation or enhancements. Excellent agreement is observed for CGAA sample analyses by Medusa3 and Medusa9 (Fig. 2), indicating a high degree of reproducibility between these instruments over $1 \sim 3$ years separation of respective analyses, and a high degree of traceability in the lineage of standard gases that were referenced. Comparison of 10 CGAA samples that were analyzed on both of these instruments showed a marginally significant difference in the Medusa9/Medusa3 ratio of $0.995 \pm 0.004$. Longer-term storage stability is demonstrated by comparison of these Medusa CGAA samples analyses with CGAA subsample analyses performed at the University of East Anglia in the UK (Oram et al., 1998). Despite $\sim 10$ years difference between analysis dates, different instruments and different calibration scales, these analyses show remarkably close agreement (Fig. 2). 


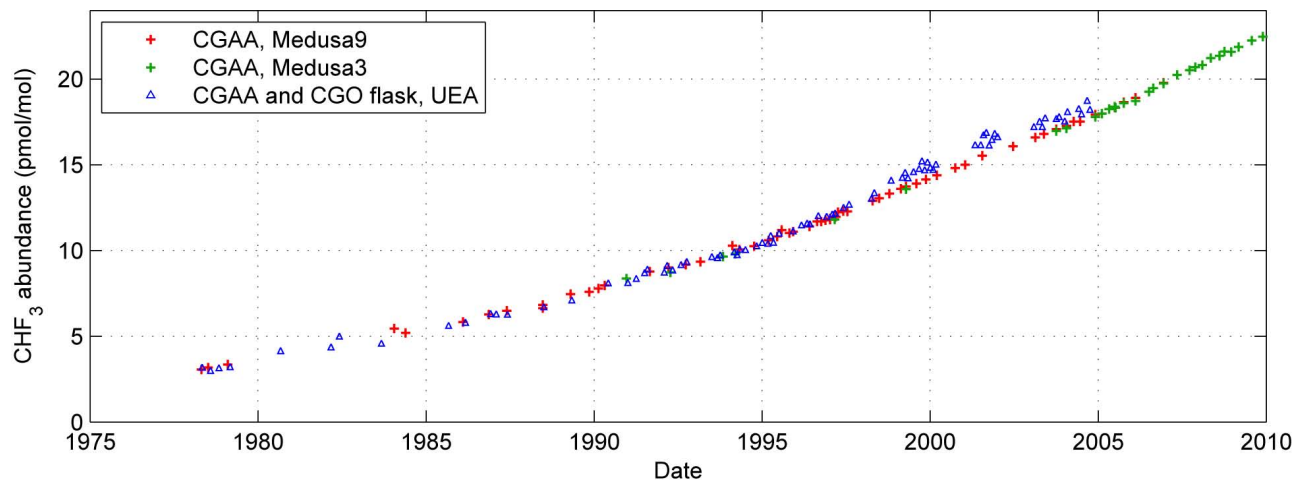

Fig. 2. HFC-23 $\left(\mathrm{CHF}_{3}\right)$ measurements of Cape Grim air archive (CGAA) samples by two nearly identical AGAGE instruments (Medusa3 and Medusa9) show excellent agreement despite the use of different instruments, different reference gases and a 1 3 years time span between respective analyses. Also shown are University of East Anglia (UEA) analyses of CGAA subsamples (Oram et al., 1998) spanning 1978 1997 and of Cape Grim (CGO) flasks collected 1997 2004 for UEA (Clerbaux et al., 2007). The AGAGE CGAA sample analyses and UEA CGAA subsample analyses show excellent agreement, despite different instruments, independent calibration scales and an elapsed time between the different instrument analyses of $\sim 10$ years. Note that the CGO flasks (samples collected for UEA after $\sim 1997$ ) show signs of HFC-23 contamination from the Viton diaphragm and valve plate in the KNF pump used to acquire these samples. CGAA sampling protocol does not utilize Viton-equipped pumps.

The low latitude sites of Barbados and American Samoa show a pronounced seasonality in atmospheric transport for a number of anthropogenic compounds of moderate to long atmospheric lifetimes and strong Northern Hemisphere emissions. Barbados is periodically influenced by air masses from further south than normal, with events of lower mole fractions of HFC-23 and other anthropogenic compounds such as HCFC-22, HFC-134a and HCFC-142b occurring particularly during the latter half of the year. American Samoa is seasonally influenced by the Northern Hemisphere, with higher mole fractions during the months of approximately November through March. These seasonal changes induce a decreased latitudinal gradient in mole fraction between Barbados and American Samoa near the end of each year, an effect that is particularly evident at the start of the in situ record in late 2007. This pattern occurs again near the end of 2008, albeit noisier and somewhat weaker for HFC-23 than for the other three aforementioned species. The more southerly air is evident in Barbados again in late 2009, but gradient assessment is precluded as the American Samoa record ends on September 29, 2009 when damage from a severe earthquake suspended operations at the observatory into the following year. Correlation of these gradients with the El Niño/Southern Oscillation (ENSO) phenomenon, which showed La Niña tendencies from mid-2007 through early 2009 then El Niño tendencies through the end of 2009 (ESRL/PSD, 2010), is not readily apparent for HFC-23 nor for the other three aforementioned halocarbons.

Lastly, it should be noted that regarding the HFC-23 in situ data, we only use analyses acquired since late 2007 in this study. At that time the Viton (fluoropolymer) diaphragms and valve plates in the KNF UN05 pumps (KNF Neuberger, Trenton, NJ), which were used to compress the ambient air from the towers, were determined to significantly contaminate the sample stream with HFC-23 (Miller et al., 2008). Accordingly, the Viton diaphragms and valve plates were then exchanged with Neoprene (chloropolymer) materials that do not exhibit this contamination. Note also that the filling of the CGAA samples does not utilize KNF pumps, thus these samples are not susceptible to contamination by HFC-23 from Viton.

\section{Reported dataset assimilation and a bottom-up HFC-23 emission history}

In this section several datasets are introduced from the Kyoto and Montreal Protocols and other sources that will be used to construct a "first guess" HFC-23 emission history for 1943-2009 to be used as an a priori emission history in our inversion modeling studies. The 1990-2008 portion of this a priori history is then examined as a "bottom-up" emission history for differences from the "top-down" history derived from the model inversions in order to assess the validities of these reported datasets. Inferences are drawn from this comparison regarding the response of the HFC- 23 emission trend to changes in developed country emissions, HCFC-22 production in developing countries and HFC- 23 emission abatement activities via the CDMs.

\subsection{UNEP and AFEAS reported datasets}

In developing an a priori emission history for the inversions, we make extensive use of HCFC-22 production data for dispersive and feedstock use from 1989 to 2008, as reported (UNEP, 2010) to the United Nations Environment 
Programme (UNEP) under Article 7 of the Montreal Protocol. These "end use" data are separated between developing and developed countries. Apparent reporting gaps in the data have been interpolated on a country-by-country basis to yield the augmented dataset used here (personal communication L. Kuijpers, UNEP, 2010). Uncertainties of the UNEP data were assigned as $\pm 25 \%$ for $1989-1992, \pm 15 \%$ for 1993-1994 and $\pm 5 \%$ for 1995-2008, where the greater uncertainties in the earlier data reflects a greater degree of augmentation.

The Alternative Fluorocarbons Environmental Acceptability Study (AFEAS) has assembled a database of production and use of HCFC-22 spanning 1943 to 2006 for all producing countries other than China, India, South Korea and Russia. Despite differences in the prescribed reporting methodologies, the actual discrepancies between AFEAS and UNEP data are relatively minor in the early years. However by the end of the 1990s the increasing production in developing countries (which do not report to AFEAS) resulted in AFEAS global production estimates diverging to $\sim 70 \%$ of the 1999-2001 UNEP global production, and to 56\% in 2003 (UNEP, 2006).

The dataset of McCulloch (2004) was constructed from various sources. For dispersive uses, AFEAS data were used for the developed world and UNEP data for the developing countries. Data for feedstock uses came from analysis of trade and technical literature on fluoropolymers production. The data taken from McCulloch (2004) are used in this study only to determine the HCFC-22 production for dispersive and feedstock uses in developed countries during 19901993 due to an apparent deficiency in UNEP dispersive use reporting.

In this study, AFEAS (2005) data will be used to represent the pre-1990 HCFC-22 dispersive use production history of developed countries. Due to the fact that feedstock production is not reported to AFEAS, we have created a proxy for feedstock production for developed countries based on scaling AFEAS pre-1990 dispersive use production by a constant ratio of McCulloch's (2004) feedstock over dispersive use production in 1990. While the estimated uncertainty of AFEAS data is $\pm 1 \%$, the combination of AFEAS dispersive production plus our estimated feedstock production is assigned an error of $\pm 15 \%$. Errors inherent in the assumption of this proxy, and in its subsequent use in combination with an estimate of the pre-1990 developed countries waste gas generation ratio, are relatively large. Therefore, this pre-1990 period will be given lesser consideration regarding the conclusions of this study. For those years after 1990, due to the increasing importance of the developing countries production component in our bottom-up analysis, we prefer to use the UNEP developing countries production data. Figure 3 illustrates the relationships between the AFEAS (AFEAS, 2005), McCulloch (2004) and UNEP data, and with the composite dataset adopted for this study.
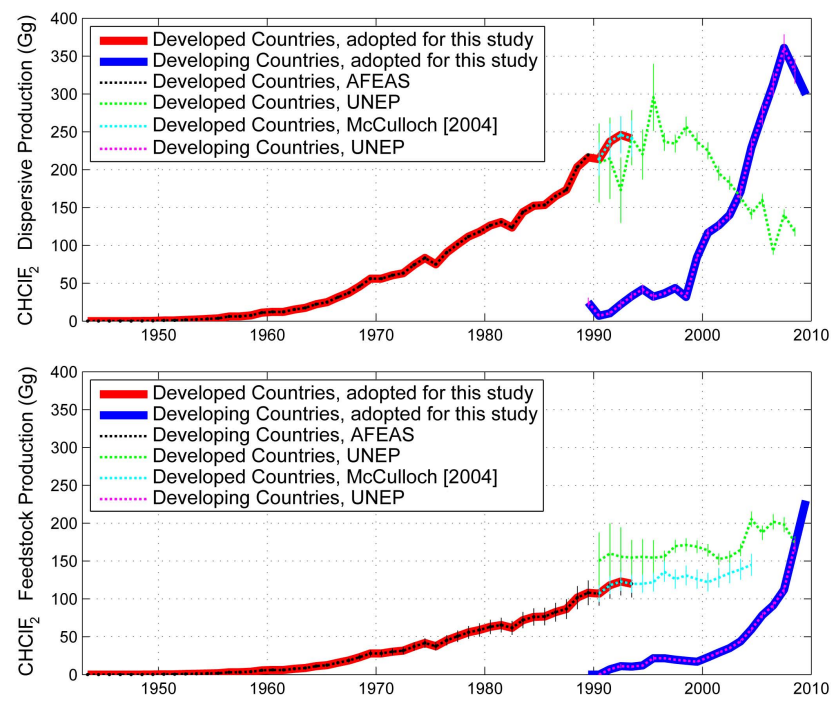

Fig. 3. Reported data for a) $\mathrm{HCFC}-22\left(\mathrm{CHClF}_{2}\right)$ production for dispersive uses and $b$ ) for feedstock use for developing and developed countries as compiled from various sources and were used "as provided". Data from UNEP, AFEAS and McCulloch (2004) are shown as dotted lines, while the red and blue solid lines denote the combined datasets adopted for use in this study. Pre-1990 feedstock data for developed countries were estimated as the AFEAS dispersive production multiplied by developed countries feedstock over dispersive production ratio (McCulloch, 2004) from 1990. These adopted data were used to create the a priori emission history for the 2-D model inversions. The subset of these data used to create the "bottom-up" HFC-23 emission history (1990-2008) is tabulated in Table 4. Uncertainties $( \pm 1 \sigma)$ for these data are denoted by error bars and are listed in Table 2 .

\subsection{Developed countries emissions reported to the UNFCCC}

HFC-23 emissions from developed countries have been reported to the UNFCCC for the period beginning 1990. Although these developed countries emission data are available on the World Wide Web (UNFCCC, 2010) through 2007, we chose to use the emissions published in Montzka et al. (2010). Their emission estimates include a 2008 datum based on "early year data" and are also augmented with additional data for the UK and Japan. As there were no reported Japanese emissions for years 1990-1994, Montzka et al. (2010) deduced these annual emissions based on total Japanese HCFC-22 production amounts and the average ratio of HFC-23 emission to HCFC-22 production calculated for Japan during $1995-2003$ of $2.3 \pm 0.5 \%$. They assigned an uncertainty of $\pm 10 \%$ to the total developed countries emissions based on uncertainties given in the Kyoto Protocol's Annex 1 greenhouse gas reports. We assume this uncertainty for all years except 1990-1994, for which we recalculate an uncertainty based on $\pm 25 \%$ uncertainties in the UNEP Japanese HCFC-22 production that they used and the uncertainty of 
$\pm 21.7 \%$ in their $2.3 \% \pm 0.5 \%$ co-production ratio. This augmentation for Japan and UK emissions principally affects the years 1990-1999, with little difference observed in later years compared to emissions taken directly from the UNFCCC website.

The first eight years of augmented HFC-23 emission data from developed countries show a nearly constant $7-8 \mathrm{Gg} / \mathrm{yr}$ emission rate. This is followed by a steady decline over approximately five years to a plateau of just under $3 \mathrm{Gg} / \mathrm{yr}$ to the end of the record in 2008. This decline is attributed to a combination of declining HCFC-22 production in developed countries, optimization of the process to lower the HFC-23/HCFC-22 co-production ratio and an increased rate of HFC-23 destruction by voluntary incineration. In the past, reporting of HFC-23 emissions to the UNFCCC was problematic, as several countries did not report HFC-23 emissions from their HCFC-22 production and some reports from other Parties lacked transparency (Irving and Branscombe, 1999). However, since 2000, there have been significant improvements and the national reports to UNFCCC under the common reporting format appear to be comprehensive and rational. Regarding the accuracy of the UNFCCC reported emissions, there is the view that these data are not intended to necessarily be "scientifically accurate". Rather, they are expected to be a homogeneous time series of data that will show improvement (IPCC, 2006). This may be interpreted as meaning that the magnitudes per se may not be accurate, but that the consistent application of reporting criteria yields an assessment of trend and variance nonetheless.

\subsection{Clean Development Mechanism}

Beginning in 2003, as part of the Clean Development Mechanism (CDM) of the UNFCCC, certain HCFC-22 production facilities in developing countries were eligible to produce Certified Emission Reduction (CER) credits for destruction of the HFC-23 they co-produced in the manufacture of HCFC-22. An approved baseline methodology, AM0001 (CDM Executive Board, 2003) and subsequent versions, that documents the parameters of HFC-23 incineration is followed to ensure that credits are issued for eligible quantities. Quantities of HFC-23 produced, as calculated by dual flow meter readings of the HFC-23 waste gas to the incinerator and HFC-23 waste stream purity analysis by GC, taking into account amounts sold, or put into or taken out of storage, are carefully documented in monitoring reports (typically spanning 2-6 months of production) along with other parameters to determine the credits that the developing country can trade. This methodology includes deductions that are made for the "carbon footprint" of the process, and with additional deductions imposed if the waste gas generation ratio and/or period HCFC-22 production exceeded the plant's historic values as documented in the project design document.

Since the first HFC-23 abatement project began in 2003, five developing countries with 19 producers, namely the Re- public of Korea, India, China, Mexico and Argentina, have produced tradeable CERs amounting to 208238 Ktonnes $\mathrm{CO}_{2}$ equivalent $\left(\mathrm{KtCO}_{2}\right.$ eq, 1 Ktonne $=1000$ Megagrams $)$ according to an April 2010 query of the CDM Pipeline database (Risoe National Laboratory, 2010). This figure is based on "issued" CERs 2003 through 2009 and at the time of the query all projects had at least one report pending in a state of "awaiting issuance request" for the latter part of 2009. These CERs may be expressed as Gigagrams (Gg) of HFC-23 by dividing the CER in $\mathrm{KtCO}_{2}$ eq by the GWP of HFC-23 (11 700, Second Assessment Report 100-year time horizon, IPCC, 1996). This result could be used as a proxy for HFC-23 incineration in developing countries, however for purposes of this study, and because of the aforementioned deductions in the CER calculation, it is preferable to know the actual annual amounts of HFC-23 that were produced but prevented from escape to the atmosphere, i.e., the annual "non-released" quantities. Therefore we examined each project monitoring report (220 reports as of March 2010) to account for HFC-23 quantities produced versus those incinerated, plus any quantities sold, or placed into or removed from storage, so that we could estimate these annual non-released quantities. As of March 2010, the 2009 report submissions (both "issued" and those "awaiting issuance request") were incomplete as 9 facilities had not yet submitted reports for late 2009 monitoring periods. To estimate the quantity of non-released HFC23 for the remainder of the year 2009 , we individually estimated amounts for each of these facilities by linear extrapolation of their reported amounts from 2008 and available 2009 data. Thus the projected remaining non-release amount total for 2009 is $0.24 \mathrm{Gg}$ or $\sim 3.0 \%$ of the reported 2009 total. This 2009 extrapolated value includes an estimate for Project \#1867 (which has yet to submit a report since its registration in November 2008) that is projected to be $\sim 0.038 \mathrm{Gg}$ in 2009 based on plant capacity. These annual total quantities of non-released HFC-23 are shown in Fig. 4 and total 23.53 Gg HFC-23 from 2003 to 2009. As can be seen from this figure, this accounting yields non-released quantities that are typically $\sim 10 \%$ larger than the HFC-23 quantities deduced from CERs alone due to the aforementioned deductions involved in the CER calculation.

In addition to the reported HFC-23 production for each monitoring period, these reports also document the corresponding HCFC-22 production. Thus we are able to accurately deduce the HFC-23/HCFC-22 co-production ratio for each report period for each project. The annual relative standard deviations of the co-production ratios from 17 facilities ranged between $9.4 \%$ and $13.7 \%$ between 2003 and 2009 . For the years 2000-2002, which precede the monitoring report periods, estimation of this ratio is based on the more limited "historical" data taken from the project design documents. Individual monitoring report ratios from 17 of the 19 projects, along with the annual mean ratios weighted by the actual production of each plant, are shown in the inset of Fig. 4. Data from 2 plants were excluded from consideration 
Table 2. Uncertainties of a priori component datasets.

\begin{tabular}{lll}
\hline Dataset & Date range & Uncertainty $( \pm 1-\sigma)$ \\
\hline AFEAS HCFC-22 production & $1943-1989 \pm 15 \%$ \\
HCFC-22 production (McCulloch, 2004) & $1990-1993 \quad \pm 15 \%$ \\
UNEP HCFC-22 production & $1989-1992 \pm 25 \%$ \\
& $1993-1994 \pm 15 \%$ \\
& $1995-2008 \quad \pm 5 \%$ \\
Developed countries HFC-23 emissions from UNFCCC & $1990-1994 \quad$ Variable, range $\pm 16.5 \%$ to $\pm 20.0 \%$ \\
& $1995-2008 \pm 10 \%$ \\
CDM HFC-23 incineration & $2003-2009 \quad \pm 2 \%$ \\
Developing countries HFC-23/HCFC-22 co-production ratio (from CDM projects) & $1960-2002 \quad \pm 15 \%$ \\
& $2003-2009$ Variable, range $\pm 9.4 \%$ to $\pm 13.7 \%$ \\
\hline
\end{tabular}

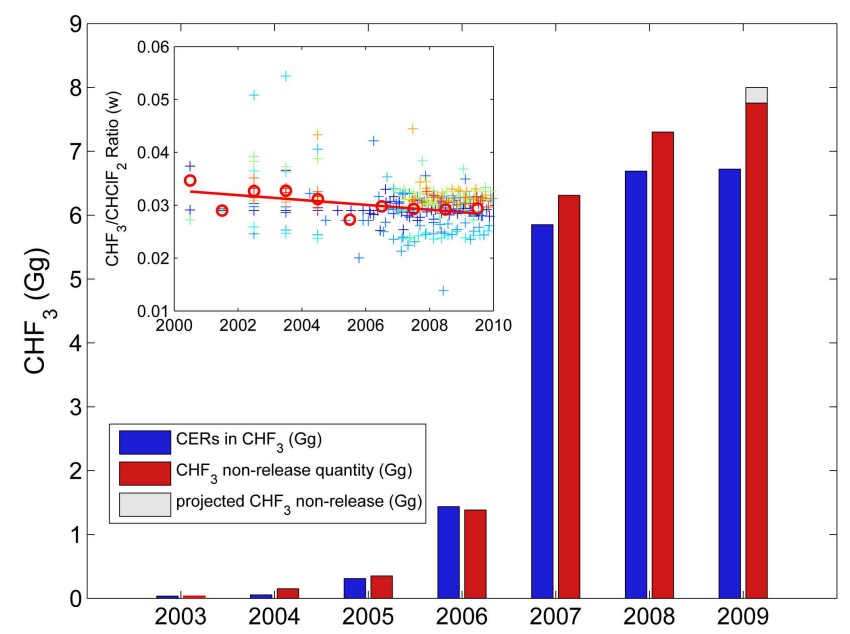

Fig. 4. Annual amounts of HFC-23 $\left(\mathrm{CHF}_{3}\right)$ involved in the Clean Development Mechanism (CDM) HFC-23 emission abatement projects. Registered projects number nineteen and consist of HCFC-22 $\left(\mathrm{CHClF}_{2}\right)$ production plants primarily in China and India. These projects have produced Certified Emission Reduction (CER) credits amounting to a total of 208238 Ktonnes $\mathrm{CO}_{2}$ equivalent (KtCO2eq) between 2003 and 2009 (shown as blue bars and converted to Gg of HFC-23). A more accurate estimate of the actual annual quantities of HFC-23 that were prevented from emission or "non-release quantities" (red bars) by the projects was determined by accounting for actual production, incineration, storage, sales and releases based on data from individual project monitoring reports. These actual annual estimates average $\sim 10 \%$ higher than those deduced from CERs alone. Thus, a total of about 23.53 Gg of HFC-23 was actually prevented from emission to the atmosphere during 2003 - 2009. This total includes an additional $0.24 \mathrm{Gg}$ ( $\sim 3 \%$ ) of HFC-23 projected to have been incinerated but not yet reported for 2009 (gray bar). The inset shows the HFC-23/HCFC-22 production ratios ("“+”) from each CDM monitoring report from 17 projects. The annual mean ratios, weighted by production amounts, are shown as red circles. because, as previously mentioned, project \#1867 has yet to report any data and reported data from the other plant resulted in inordinately low waste gas ratios that are rarely attained even with the most optimized of processes. For estimation of the co-production ratio prior to 2000 a linear extrapolation of the 2000-2009 ratio data is used. We use these annual mean ratios, in combination with HCFC22 production as given by UNEP, in the next section to estimate the developing countries' HFC-23 production. Based on a 2008 total HCFC-22 production of $256.0 \mathrm{Gg}$ from the CDM monitoring reports and the UNEP 2008 developing countries total production of $501 \mathrm{Gg}$, we attribute $\sim 51 \%$ of the total developing countries HCFC-22 production to the CDM projects. There are opposing viewpoints that suggest that CDM projects would have either higher or lower coproduction ratios compared to non-CDM plants in the developing world. A discussion of this debate is outside the scope of this manuscript. In view of this non-resolved difference in expectations of relative co-production ratios, and considering the large sampling of developing countries facilities that the CDM projects represent, we make the simple assumption that these CDM annual mean HFC-23/HCFC22 co-production ratios are representative of the mean from all developing countries producers. Given the expectation of the CDM Executive Board that this CDM methodology yields low uncertainties, we conservatively assign $\pm 2 \%$ to the CDM annual total quantities of non-released HFC-23.

\subsection{Assembling a bottom-up HFC-23 emission history}

The data compiled in Sects. 3.1 to 3.3 above are now used to produce an a priori HFC-23 emission estimate for the inversion modeling. The 1990-2008 segment of this a priori will later be considered as a "bottom-up" emission history for comparison with our top-down emission history. Construction of the a priori may be considered in two parts and is illustrated in Fig. 5. First, on the assumption that the emissions in the early years 1943 to 1989 were attributable to developed countries only, they were deduced as the AFEAS HCFC-22 


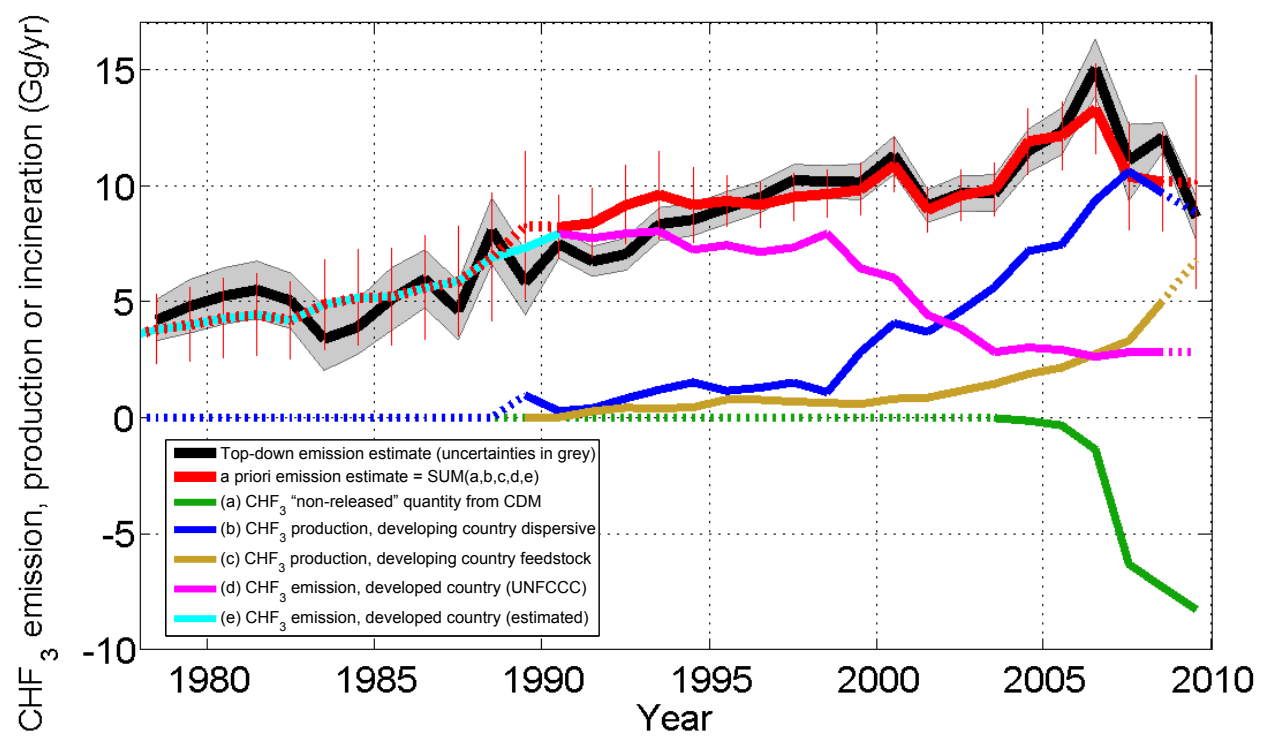

Fig. 5. Global HFC-23 $\left(\mathrm{CHF}_{3}\right)$ emissions from a "top-down" method (black line, $68 \%$ uncertainties shaded gray), which are based on inversion of atmospheric observations using the 2-D 12-box model, compared to the a priori emission estimate (red line, both dotted and solid, with $\pm 1-\sigma$ uncertainties). The a priori represents the sum of the contributions from developed and developing countries, as compiled from data submitted to the United Nations Framework Convention on Climate Change (UNFCCC) and the Clean Development Mechanism (CDM), and calculated from HCFC-22 $\left(\mathrm{CHClF}_{2}\right)$ production data from the United Nations Environment Programme (UNEP) and the Alternative Fluorocarbons Environmental Acceptability Study (AFEAS). A segment of the a priori (1990-2008, solid red line) is of sufficient certainty to be useful as a "bottom-up" emission estimate in a comparison to the top-down history. The observed agreement suggests a level of credibility to the UNEP HCFC-22 production data, the HFC-23 emissions reported to the UNFCCC and the incinerated quantities of HFC-23 reported by the CDMs.

production data multiplied by the developed countries HFC23/HCFC-22 co-production ratio. This ratio was estimated as $0.0225 \pm 0.0071$, based on the four-year (1990-1993) average ratio of developed countries' HFC-23 emissions (from UNFCCC and assumed equal to production) over developed countries total (dispersive plus feedstock) HCFC-22 production from McCulloch (2004).

The second part of the a priori emission history, which spans 1990-2008, is assembled from UNFCCC, UNEP and CDM data of generally greater certainty compared to the earlier period. This history is the sum of the reported plus the augmented HFC-23 emissions from the UNFCCC and an estimate of developing countries' emissions. This developing countries' estimate is the sum of their HCFC-22 production (UNEP, 2010) for dispersive and feedstock uses, multiplied by the annual mean ratios of their HFC-23/HCFC-22 coproduction, minus the actual HFC-23 non-released amounts from the CDM projects, the latter two quantities having been derived in Sect. 3.3. The resulting a priori history is shown in Fig. 5, with the segment 1990-2008 that is considered our "bottom-up" history indicated as a solid red line, and all other years shown as a dotted red line, including an extrapolated 2009 datum. These bottom-up estimates are tabulated in Table 4 . The overall uncertainties in this history were estimated based on uncertainties assigned to the individual components (see Table 2).
In creating the emission estimate for developing countries above, some minor sources and losses have been assumed to be negligible. For example, any quantity of HFC-23 derived from HCFC-22 production and was consumed as feedstock in the production of Halon-1301 $\left(\mathrm{CF}_{3} \mathrm{Br}\right)$ would be an additional loss mechanism not accounted for in our calculation. Developed countries ceased production of Halons in 1994 and developing countries are scheduled to phase-out production of Halons by 2010 under the Montreal Protocol. Production of all types of Halons in China had been reduced from 30060 ODP tons in 1998 to 1000 ODP tons in 2008 (World Bank, 2009), indicating this to be a negligible component in our calculations. Regarding other uses, McCulloch and Lindley (2007) suggest that "current emissions directly from HFC-23 use, e.g., from fire extinguishing applications, are trivial relative to global production". Lastly, semiconductor use of HFC-23 is insignificant and becoming out-dated, as substrates become larger, better etchants and cleaners are now utilized and the most modern lines use $F_{2}$. Furthermore, especially in the semiconductor industry, use does not equal emission, as destruction efficiencies are greater than 90\% (Barthos et al., 2006).

We compared our bottom-up 2004-2005 mean HFC-23 emission rate of $9.25 \mathrm{Gg} / \mathrm{yr}$ for developing countries with a top-down estimate from Yokouchi et al. (2006), which is a May 2004 to May 2005 emission rate of $10( \pm 5) \mathrm{Gg} / \mathrm{yr}$ 
HFC-23 attributed to China. They derived this estimate using a tracer-ratio technique with a tagged simulation in a $3 \mathrm{D}$ transport model. To determine approximately how much of our developing countries 2004-2005 mean emission estimate should be attributable to China, we note that, at that time there were only seven non-Chinese facilities in the developing world that were not incinerating their HFC-23. Based on our CDM accounting and assuming a Venezuelan plant capacity of $2000 \mathrm{Mg} \mathrm{HCFC}-22 / \mathrm{yr}$, then these seven plants (four in India, one each in Argentina, Mexico and Venezuela) produced amounts of HCFC-22 in 2007-2009 that were equivalent to $\sim 10 \%$ of the total HCFC-22 production in the developing world. Assuming this same percentage in 2004-2005, then $\sim 90 \%$ of our bottom-up developing countries' emissions $(\sim 8.3 \mathrm{Gg} / \mathrm{yr})$ should have come from China alone, for an emission estimate that is lower than, but within uncertainties, of the Yokouchi et al. (2006) estimate.

\section{Modeling studies}

The AGAGE 2-D atmospheric 12-box chemical transport model has been used extensively in halocarbon emission estimation studies (e.g., Cunnold et al., 1983, 1994) and is used here to simulate atmospheric mole fractions and sensitivities of these mole fractions to changes in emissions. The global locations of the AGAGE remote stations were specifically chosen so as to sample well-mixed "baseline" air masses that would represent the mole fractions corresponding to each of the four equal-volume lower tropospheric boxes of the model (the model has vertical divisions at $1000 \mathrm{hPa}, 500 \mathrm{hPa}$, $200 \mathrm{hPa}$ and $0 \mathrm{hPa}$ and represents the latitudinal bands $90^{\circ}-$ $30^{\circ} \mathrm{S}, 30^{\circ}-0^{\circ} \mathrm{S}, 0^{\circ}-30^{\circ} \mathrm{N}$ and $\left.30^{\circ}-90^{\circ} \mathrm{N}\right)$. Emission estimates were produced using the AGAGE in situ and CGAA HFC-23 measurements, and the modeled mole fractions and sensitivities, with an inverse methodology based on an optimal linear recursive least squares filter of the Kalman type (Gelb, 1974; Prinn, 2000). The construction of the a priori used in the inverse modeling is described in Sect. 3.4.

The mole fractions derived using the a priori emissions, i.e. without the optimization provided by the Kalman filter, are shown in Fig. 1 as dashed lines. The agreement observed between the a priori mole fraction growth rate and the actual observations is our first indication that the components of the bottom-up history (i.e., the UNFCCC, UNEP and CDM data) are reasonably accurate. We discuss below the agreement observed between the a priori emission history and the optimized emissions in a more detailed examination.

An important aspect of this inverse method is its ability to produce estimates of the uncertainties in the resulting emissions, and to account for measurement and modeling errors. The error of each data point used in the inversion includes true measurement errors, along with errors associated with sampling frequency and model/data mismatch, and is calcu- lated as the square root of the sum of the squares of the individual components (e.g. Chen and Prinn, 2006). For the measurement precision of the CGAA we use the actual analytical precisions, and for the in situ data we use $0.10 \mathrm{pmol} \mathrm{mol}^{-1}$ ( $0.46 \%$ RSD), which is the mean precision of one full year (2006) of in situ reference gas measurements at the AGAGE station in Trinidad Head, California (Miller et al., 2008). When more than one measurement is available in a given month, the precision error is correspondingly reduced by the square root of the number of measurements. As an estimate of the error associated with the scale propagation, we have as a proxy the precisions of the R1 values (see Analytical Studies above) for each standard gas as determined by analyses prior to and subsequent to field service. For HFC-23, the mean R1 scale precision was $0.27 \pm 0.20 \%$ RSD for 56 different standard tank R1 calibrations. The sampling frequency error is a measure of how well the measurements sample the monthly mean mole fractions simulated by the 12-box model, and is taken to be the monthly baseline standard deviation divided by the square root of the number of measurements. For the archive measurements where we do not have high frequency variability information, this term is estimated by scaling the mean baseline standard deviation from the high-frequency measurements by the ratio of the in situ and archive mole fractions. The model/data mismatch error is a measure of how well the model can be expected to reproduce the measurements. We estimate this term as the standard deviation of the measured monthly baseline variability, as a measure of the inability of the model to simulate sub-monthly mole fraction variations.

To simulate the destruction of HFC-23 in the atmosphere we consider its reaction with the hydroxyl radical $(\mathrm{OH})$ in the troposphere and assume a lifetime in the stratosphere. The temperature dependent rate of reaction with $\mathrm{OH}$ was taken from the Jet Propulsion Laboratory (JPL) data evaluation 15 (Sander et al., 2006). We use a stratospheric lifetime of 2347 years, as derived by Naik et al. (2000), and no ocean sink was included.

Annual emissions were solved for in each semihemisphere from 1978, when the first measurements were available, through to the end of 2009 . The initial concentration in 1975 was also derived in the inversion, and the emissions from 1975-1977 were assumed to be equal to that derived in 1978.

The error in the deduced emissions includes both that derived by the Kalman filter and an estimate of the modeling uncertainties. The latter term is estimated by performing the inversion 1000 times, each time with randomly perturbed transport and chemical reaction parameters. The standard deviations of the (Gaussian) perturbations were taken from both the original box model parameter estimation inversions and the JPL evaluation. The modeling error is then estimated as the standard deviation of this set of inversions. Figure S2 in the supplementary materials shows the residual differences between the monthly mean mole fraction observations 
and the model optimized mole fractions for the four lower tropospheric boxes of the model.

The a priori latitudinal distribution of the emissions was initially estimated to be as derived for HCFC-22 by Miller et al. (1998), who estimated that approximately $89 \%$ of emissions originated in the $\mathrm{NH}$. It was found that the derived global annual emissions were generally insensitive to the prior latitudinal distribution, apart from those in 2006 and 2007, probably as a result of the transition from SH-only to global measurements during 2007. To incorporate this sensitivity into our emissions estimates, in each of the perturbations used to estimate modeling error we also randomly perturbed the percentage of prior emissions in the $\mathrm{NH}$ by $\pm 10 \%$ compared to the Miller et al. (1998) estimates (the $\pm 10 \%$ range was sampled uniformly). Our "top-down" global emissions error therefore includes three components: errors derived from the Kalman filter, modeling error and sensitivity of the inversion to the prior spatial distribution.

Given the differences in sampling frequency throughout the record, some parts of the derived emission time series may be considered more reliable than others. We paid particular attention to the 2006 emission estimate because it occurs just before the in situ measurements come online. One may expect the "top-down" values to be sensitive to the a priori emissions distribution, model transport parameter uncertainty and/or errors in the scale propagation. To test the reliability of these errors, we produced several additional emissions estimates including an inversion using only CGAA and CGO measurements, and separate inversions excluding one or more $\mathrm{NH}$ or tropical stations. Whilst these inversions produced slightly different results, none were found to deviate significantly from the emissions and associated errors presented in Fig. 1. Given the much higher measurement frequency in all semi-hemispheres, we can be more confident in the emissions down-turn presented for 2008-2009, as reflected in the smaller error in these years.

\section{Results: HFC-23 abundance, trend and emissions}

The modeled 2009 annual global lower-tropospheric mean background abundance is 22.6 ( $\pm 0.21-\sigma$ confidence interval) pmol mol${ }^{-1}$. HFC-23 shows a monotonically increasing trend in atmospheric mole fraction since 1978, with a marked acceleration during 2004-2006 (Fig. 1 and Table 3). Accordingly, the modeled HFC-23 emissions show growth over much of this period. Of particular note is the marked increase in global HFC-23 emissions to $15.0(+1.3 /-1.2,68 \%$ confidence interval) $\mathrm{Gg} / \mathrm{yr}$ by 2006 , well above an apparent $1997-$ 2003 "plateau" mean of $10.0 \pm 0.7 \mathrm{Gg} / \mathrm{yr}$ for an increase of $\sim 50 \%$. This observation is similar in magnitude and timing to that reported by Montzka et al. (2010) who report emissions based on firn-air and ambient air measurements from Antarctica. Their mean global HFC-23 emission of $13.5 \pm 2 \mathrm{Gg} / \mathrm{yr}$, which is an average for $2006-2008$, is $\sim 50 \%$ higher than their $8.7 \pm 1 \mathrm{Gg} / \mathrm{yr}$ mean emission rate derived for the 1990s.

However, following this 2004-2006 acceleration, the AGAGE atmospheric abundance record shows a deceleration in the atmospheric HFC-23 growth rate after 2006. Accordingly, our inverse model results indicate a $43 \%$ decrease in HFC-23 emissions from 2006 to 2009. The 2009 emission estimate of $8.6(+0.9 /-1.0) \mathrm{Gg} / \mathrm{yr}$ is $\sim 14 \%(\sim 1.4 \mathrm{Gg})$ below the mean of the 1997-2003 plateau. Global HFC-23 emissions have not been this low since 1994, one and a half decades ago. We discuss some of the factors driving this HFC-23 emission decrease in the following section.

A further comparison with other published HFC-23 emission estimates is shown in Fig. 6. The Oram et al. (1998) emissions are based on GC/MSD analyses of CGAA subsamples at the University of East Anglia (UEA), thus it is not coincidence that they show reasonable agreement with the AGAGE 2-D 12-box model early years results that are based on the CGAA "parent" samples. However, the extension of these emission estimates (IPCC, 2005) included flask samples later acquired for UEA at Cape Grim by pressurization with a KNF UN05 pump equipped with a Viton diaphragm and valve plate (P. Steele, personal communication, 2009). This choice of pump material likely led to the contamination that is apparent by the enhancements in these flask samples, as expected from the aforementioned out gassing of HFC23 by Viton. While the Oram et al. (1998) CGAA subsample analyses show remarkable agreement with the Medusa9 CGAA sample analyses (see Fig. 2), the UEA flask data (Clerbaux et al., 2007) after $\sim 1997$ are $\sim 1$ ppt higher than subsequent CGAA samples acquired during the same period as analyzed by Medusa9 and Medusa3. This transition from CGAA subsamples to UEA Cape Grim flask samples caused the resulting IPCC 2005 emission estimates to increase too rapidly, by about $1 \sim 3 \mathrm{Gg} / \mathrm{yr}$ (10-30\%) during 1998-2002, relative to the AGAGE emission estimates.

\section{Discussion: quantifying the factors driving recent changes in the HFC-23 trend}

As shown in Fig. 5, there is agreement within uncertainties between the top-down and a priori histories for all years from 1978 to 2008 . The a priori estimates in the early years 1978 1989 are controlled by emissions deduced from AFEAS data and the assumed developed countries HFC-23/HCFC-22 coproduction ratio. These early years were intended solely for use in the inversions, and as their uncertainties are quite large, we do not further consider their interpretation.

Beginning in 1990, the bottom-up estimates are controlled by emissions from the developed countries reporting to the UNFCCC and in the later years (after $\sim 2002$ ) by rapidly increasing HCFC-22 production in developing countries. The agreement observed between the later years of the bottom-up and top-down HFC-23 emission histories yields confidence 
Table 3. Annual mean lower-troposphere global mean mole fractions, growth rates and emissions for HFC-23 $\left(\mathrm{CHF}_{3}\right)$ from $2-\mathrm{D} 12-$ box model inversions of AGAGE observations.

\begin{tabular}{|c|c|c|c|c|}
\hline Year & $\begin{array}{l}\text { Global mean } \mathrm{CHF}_{3} \\
\text { mole fraction } \\
(\mathrm{pmol} / \mathrm{mol})\end{array}$ & $\begin{array}{l}\text { Global } \mathrm{CHF}_{3} \text { growth } \\
\text { rate }(\mathrm{pmol} / \mathrm{mol} / \mathrm{yr})\end{array}$ & $\begin{array}{l}\text { Global annual } \mathrm{CHF}_{3} \\
\text { emissions }(\mathrm{Gg} / \mathrm{yr})\end{array}$ & $\begin{array}{l}\text { Global annual } \mathrm{CHF}_{3} \text { emission } \\
68 \% \text { uncertainty }(\mathrm{Gg} / \mathrm{yr})\end{array}$ \\
\hline 1978 & 3.37 & 0.33 & 4.2 & $+0.9 /-0.9$ \\
\hline 1979 & 3.73 & 0.39 & 4.8 & $+1.2 /-1.2$ \\
\hline 1980 & 4.13 & 0.42 & 5.2 & $+1.2 /-1.2$ \\
\hline 1981 & 4.56 & 0.44 & 5.5 & $+1.2 /-1.2$ \\
\hline 1982 & 4.97 & 0.38 & 5.0 & $+1.2 /-1.2$ \\
\hline 1983 & 5.27 & 0.22 & 3.4 & $+1.4 /-1.4$ \\
\hline 1984 & 5.53 & 0.29 & 3.9 & $+1.2 /-1.2$ \\
\hline 1985 & 5.87 & 0.41 & 5.1 & $+1.4 /-1.3$ \\
\hline 1986 & 6.31 & 0.48 & 5.9 & $+1.2 /-1.3$ \\
\hline 1987 & 6.71 & 0.34 & 4.6 & $+1.3 /-1.3$ \\
\hline 1988 & 7.22 & 0.67 & 8.0 & $+1.4 /-1.4$ \\
\hline 1989 & 7.76 & 0.42 & 5.8 & $+1.4 /-1.4$ \\
\hline 1990 & 8.28 & 0.59 & 7.4 & $+0.6 /-0.6$ \\
\hline 1991 & 8.82 & 0.50 & 6.7 & $+0.7 /-0.6$ \\
\hline 1992 & 9.34 & 0.54 & 7.0 & $+0.7 /-0.7$ \\
\hline 1993 & 9.94 & 0.66 & 8.3 & $+0.7 /-0.7$ \\
\hline 1994 & 10.60 & 0.66 & 8.5 & $+0.7 /-0.7$ \\
\hline 1995 & 11.27 & 0.70 & 9.0 & $+0.7 /-0.7$ \\
\hline 1996 & 11.99 & 0.73 & 9.5 & $+0.7 /-0.7$ \\
\hline 1997 & 12.75 & 0.79 & 10.2 & $+0.7 /-0.7$ \\
\hline 1998 & 13.54 & 0.77 & 10.1 & $+0.7 /-0.7$ \\
\hline 1999 & 14.30 & 0.77 & 10.1 & $+0.8 /-0.8$ \\
\hline 2000 & 15.12 & 0.87 & 11.3 & $+0.8 /-0.8$ \\
\hline 2001 & 15.88 & 0.64 & 9.1 & $+0.7 /-0.7$ \\
\hline 2002 & 16.56 & 0.71 & 9.6 & $+0.8 /-0.8$ \\
\hline 2003 & 17.26 & 0.71 & 9.6 & $+0.8 /-0.8$ \\
\hline 2004 & 18.06 & 0.89 & 11.5 & $+0.9 /-0.9$ \\
\hline 2005 & 18.97 & 0.95 & 12.3 & $+1.0 /-1.0$ \\
\hline 2006 & 20.05 & 1.19 & 15.0 & $+1.3 /-1.2$ \\
\hline 2007 & 21.02 & 0.77 & 11.0 & $+1.5 /-1.7$ \\
\hline 2008 & 21.85 & 0.88 & 12.0 & $+0.6 /-0.7$ \\
\hline 2009 & 22.56 & 0.53 & 8.6 & $+0.9 /-1.0$ \\
\hline
\end{tabular}

that the major components determining these emissions have been accounted for in the bottom-up history. It also suggests a level of credibility for each of the reported datasets (i.e., the developed countries' HFC-23 emissions as reported to the UNFCCC, UNEP HCFC-22 production for developing countries and amounts of HFC-23 non-release calculated from the CDMs), assuming exclusion of the possibility of compensation by opposite signed errors among the datasets. In the 1990s, HFC-23 emissions from developed countries dominated all other sources, then began to decline and eventually became fairly constant during 2003-2008. By this point, with developed countries' emissions essentially at a plateau, the major factor controlling the annual dynamics of global HFC-23 emissions became the historical rise of developing countries' HCFC-22 dispersive use production, which peaked in 2007. But incineration by CDM projects became a larger component during 2007-2009, reducing global HFC23 emissions despite a high HCFC-22 dispersive production and a rapidly rising HCFC-22 feedstock production, both in the developing world. With the dispersive use production component scheduled for a faster phase-out after the 2007 Amendment to the Montreal Protocol, it is the unrestricted feedstock component that is poised to become the dominant source of HFC-23 production. Within the Montreal Protocol HCFC phase-out timeframe of the next two decades, the controlling factor determining whether there is resurgence or continued decline in HFC-23 emissions may be the extent to which incineration can keep pace to counteract potential growth in feedstock production. 
Table 4. HCFC-22 $\left(\mathrm{CHClF}_{2}\right)$ production and HFC-23 $\left(\mathrm{CHF}_{3}\right)$ production, emissions and incineration for developing countries, developed countries and global total. The sources of HCFC-22 production data are indicated by footnote letters "a"-"c" following the numerical data.

\begin{tabular}{|c|c|c|c|c|c|c|c|c|c|c|}
\hline Year & $\begin{array}{l}\text { Developed } \\
\text { countries } \\
\text { dispersive } \\
\mathrm{CHClF}_{2} \text { prod. } \\
(\mathrm{Gg})\end{array}$ & $\begin{array}{l}\text { Developed } \\
\text { countries feed- } \\
\text { stock } \mathrm{CHClF}_{2} \\
\text { prod. }(\mathrm{Gg})\end{array}$ & $\begin{array}{l}\text { Developing } \\
\text { countries } \\
\text { dispersive } \\
\mathrm{CHClF}_{2} \\
\text { prod. }^{\text {b }}(\mathrm{Gg})\end{array}$ & $\begin{array}{l}\text { Developing } \\
\text { countries feed- } \\
\text { stock } \mathrm{CHClF}_{2} \\
\text { prod. }^{\mathrm{b}}(\mathrm{Gg})\end{array}$ & $\begin{array}{l}\text { Developed } \\
\text { countries }(\mathrm{UN}- \\
\text { FCCC) } \mathrm{CHF}_{3} \\
\text { emissions }{ }^{\mathrm{c}} \\
(\mathrm{Gg})\end{array}$ & $\begin{array}{l}\text { Developing } \\
\text { countries } \\
\mathrm{CHF}_{3} \text { prod. } \\
\text { from disper- } \\
\text { sive } \mathrm{CHClF}_{2} \\
\text { prod. }(\mathrm{Gg})\end{array}$ & $\begin{array}{l}\text { Developing } \\
\text { countries } \\
\mathrm{CHF}_{3} \text { prod. } \\
\text { from feedstock } \\
\mathrm{CHClF}_{2} \text { prod. } \\
(\mathrm{Gg})\end{array}$ & $\begin{array}{l}\mathrm{CDM} \text { "non- } \\
\text { released" } \\
\mathrm{CHF}_{3}(\mathrm{Gg})\end{array}$ & $\begin{array}{l}\mathrm{CDM} \\
\mathrm{CHF}_{3} / \mathrm{CHClF}_{2} \\
\text { co-production } \\
\text { ratio }(\%)\end{array}$ & $\begin{array}{l}\text { Global bottom- } \\
\text { up } \mathrm{CHF}_{3} \text { emis- } \\
\text { sions }(\mathrm{Gg} / \mathrm{yr})\end{array}$ \\
\hline 1990 & $214^{\mathrm{a}}$ & $107^{\mathrm{a}}$ & 7 & 0 & 7.9 & 0.27 & 0.00 & - & 3.74 & 8.2 \\
\hline 1991 & $237^{\mathrm{a}}$ & $118^{\mathrm{a}}$ & 10 & 7 & 7.7 & 0.39 & 0.26 & - & 3.69 & 8.3 \\
\hline 1992 & $246^{\mathrm{a}}$ & $123^{\mathrm{a}}$ & 22 & 11 & 7.9 & 0.81 & 0.41 & - & 3.65 & 9.1 \\
\hline 1993 & $241^{\mathrm{a}}$ & $120^{\mathrm{a}}$ & 33 & 11 & 8.0 & 1.19 & 0.38 & - & 3.60 & 9.6 \\
\hline 1994 & $220^{\mathrm{b}}$ & $120^{\mathrm{b}}$ & 42 & 12 & 7.2 & 1.50 & 0.43 & - & 3.56 & 9.1 \\
\hline 1995 & $296^{\mathrm{b}}$ & $122^{\mathrm{b}}$ & 32 & 22 & 7.4 & 1.14 & 0.76 & - & 3.51 & 9.3 \\
\hline 1996 & $237^{\mathrm{b}}$ & $156^{\mathrm{b}}$ & 37 & 22 & 7.1 & 1.27 & 0.75 & - & 3.46 & 9.1 \\
\hline 1997 & $234^{\mathrm{b}}$ & $170^{\mathrm{b}}$ & 44 & 20 & 7.3 & 1.50 & 0.67 & - & 3.42 & 9.5 \\
\hline 1998 & $257^{\mathrm{b}}$ & $171^{\mathrm{b}}$ & 32 & 18 & 7.9 & 1.07 & 0.62 & - & 3.37 & 9.6 \\
\hline 1999 & $237^{\mathrm{b}}$ & $169^{\mathrm{b}}$ & 84 & 17 & 6.4 & 2.81 & 0.57 & - & 3.33 & 9.8 \\
\hline 2000 & $225^{\mathrm{b}}$ & $164^{\mathrm{b}}$ & 117 & 23 & 6.0 & 4.04 & 0.79 & - & 3.47 & 10.8 \\
\hline 2001 & $195^{\mathrm{b}}$ & $152^{\mathrm{b}}$ & 126 & 29 & 4.4 & 3.67 & 0.84 & - & 2.90 & 8.9 \\
\hline 2002 & $183^{\mathrm{b}}$ & $156^{\mathrm{b}}$ & 140 & 35 & 3.8 & 4.59 & 1.15 & - & 3.27 & 9.5 \\
\hline 2003 & $164^{\mathrm{b}}$ & $165^{\mathrm{b}}$ & 171 & 44 & 2.8 & 5.60 & 1.44 & 0.036 & 3.27 & 9.8 \\
\hline 2004 & $142^{\mathrm{b}}$ & $205^{\mathrm{b}}$ & 229 & 60 & 3.0 & 7.15 & 1.86 & 0.151 & 3.12 & 11.9 \\
\hline 2005 & $160^{\mathrm{b}}$ & $187^{\mathrm{b}}$ & 272 & 78 & 2.9 & 7.42 & 2.14 & 0.351 & 2.73 & 12.1 \\
\hline 2006 & $92^{\mathrm{b}}$ & $202^{\mathrm{b}}$ & 313 & 91 & 2.6 & 9.31 & 2.72 & 1.384 & 2.98 & 13.3 \\
\hline 2007 & $141^{\mathrm{b}}$ & $198^{\mathrm{b}}$ & 361 & 112 & 2.8 & 10.57 & 3.29 & 6.310 & 2.93 & 10.3 \\
\hline 2008 & $118^{\mathrm{b}}$ & $174^{\mathrm{b}}$ & 330 & 171 & 2.8 & 9.63 & 4.99 & 7.301 & 2.92 & 10.1 \\
\hline 2009 & - & - & - & - & - & - & - & 8.000 & 2.94 & - \\
\hline
\end{tabular}

${ }^{\mathrm{a}}$ McCulloch (2004); ${ }^{\mathrm{b}}$ UNEP (2010); ${ }^{\mathrm{c}}$ Montzka et al. (2010).

\section{Conclusions}

HFC-23 $\left(\mathrm{CHF}_{3}\right)$ is an unavoidable by-product (at $\sim 1.4$ to $\sim 4 \%)$ in the industrial manufacture of HCFC-22 $\left(\mathrm{CHClF}_{2}\right)$ and historically has been simply vented to the atmosphere following manufacture. HCFC-22 is used extensively in refrigeration, air conditioning and extruded polystyrene (XPS) foam applications, from which it ultimately escapes to the atmosphere over time scales of up to $\sim 20$ years. HCFC-22 is also used as a feedstock in fluoropolymer production, from which emissions are considered negligible in the context of this analysis.

AGAGE observations of HFC-23 atmospheric mole fractions measured by in situ Medusa instruments at five remote sites around the globe and in archived air samples from Cape Grim, Tasmania, are presented. These observations provide an atmospheric history of unprecedented precision, consistency and traceability that shows monotonically increasing mole fractions over the past three decades.

An inversion technique using the Kalman filter and the AGAGE 2-D atmospheric 12-box model yields model mole fractions and annual HFC-23 emissions with rigorously determined uncertainties. The model 2009 annual mean global lower-tropospheric mean background abundance is $22.6( \pm 0.2) \mathrm{pmol} \mathrm{mol}^{-1}$. The modeled emissions show a plateau during 1997-2003, followed by a rapid $\sim 50 \%$ increase to a peak of $15.0(+1.3 /-1.2) \mathrm{Gg} / \mathrm{yr}$ in 2006 , consistent with the results of Montzka et al. (2010). Following this peak, emissions of HFC-23 declined rapidly over the three subsequent years to $8.6(+0.9 /-1.0) \mathrm{Gg} / \mathrm{yr}$ in 2009 , a low level not seen in the prior 15 years.

To investigate the response of HFC-23 emissions to HCFC-22 production and recent HFC-23 emission abatement measures, a bottom-up HFC-23 emission history was constructed for comparison with our top-down HFC-23 emission history. The bottom-up history relies on HCFC22 data provided by UNEP up to 2008, on HFC-23 data provided by UNFCCC for developed countries emissions to 2008, on CDM HFC-23 incineration monitoring reports for 2003-2009 and on annual HFC-23/HCFC-22 co-production ratios for developing countries deduced from these CDM reports. The top-down versus bottom-up HFC-23 emission history comparison shows agreement within stated uncertainties for all years, with particularly close agreement during 1995-2005. The bottom-up history shows small, statistically insignificant departures to lower values in 2006 and 2008. Overall, this level of agreement supports a reasonable confidence in the HFC-23 emission data reported to the UNFCCC for developed countries and for HFC-23 incineration data reported by $\mathrm{CDM}$ projects, and for data reported to UNEP under Article 7 of the Montreal Protocol. In the 1990s HFC-23 emissions from developed countries dominated all other factors controlling emissions, and thereafter they began to decline to an eventual six year plateau. From the beginning of that plateau, the major factor controlling the annual dynamics of global HFC-23 emissions became the historical rise of HCFC-22 production for dispersive uses in developing countries to a peak in 2007. But incineration via CDM projects became a 


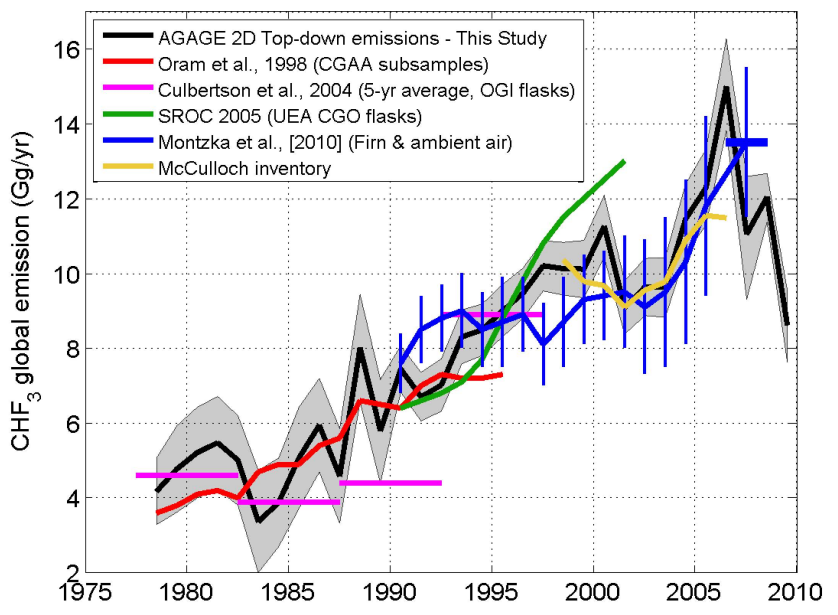

Fig. 6. Comparison of AGAGE HFC-23 $\left(\mathrm{CHF}_{3}\right)$ global emissions with other published results. The AGAGE 2-D 12-box model inversions of AGAGE in situ and Cape Grim air archive data captures the 2001 to 2006 rapid rise in HFC-23 emissions that was first reported in a Montzka et al. (2010) study that was based on firn air and ambient air measurements. The AGAGE history resolves the rapid decrease in emissions to 2009. The estimates of Oram et al. (1998) are derived from UEA GC/MSD measurements of subsamples of the CGAA, thus bear strong resemblance to the AGAGE estimate. However, the extension of the UEA emissions beyond 1998 as given in the IPCC (2005) was based on flask samples that were contaminated during filling (see text for details) and yielding steeper growth thereafter. The McCulloch (2004) estimates based on inventories show good agreement with AGAGE emissions for most of their common record, but decline as unaccounted production in developing countries begins to dominate global production. The Culbertson et al. (2004) 5-year average HFC-23 emission estimates agree well with other estimates for most years, but the $1990 \pm 2.5$ year average emission appears low.

larger component during 2007-2009, reducing global HFC23 emissions despite both a high HCFC-22 dispersive production and a rapidly rising feedstock production, both in the developing world. Within the Montreal Protocol HCFC phase-out timeframe of the next two decades, the controlling factor determining whether there is resurgence or continued decline in HFC-23 emissions may be the extent to which incineration can keep pace to counteract potential growth in feedstock production. This work underlines the importance of being able to use atmospheric measurements and model simulations to estimate emissions of gases such as HFC-23, thereby providing an independent verification methodology for reported emissions.

\section{Supplementary material related to this article is available online at: http://www.atmos-chem-phys.net/10/7875/2010/ acp-10-7875-2010-supplement.pdf.}

Acknowledgements. The authors wish to acknowledge the strong support provided by the AGAGE remote field operators $M$. Cunningham, R. Dickau, C. Rickard, P. Sealy and G. Spain. Special acknowledgment goes to the late L. W. Porter for his meticulous work and creative contributions in the CGAA sampling and analysis, and for providing field support for decades of in situ and flask sampling. We gratefully acknowledge S. A. Montzka, D. W. Fahey and M. McFarland for invaluable discussions. The international AGAGE research program is supported by the NASA Upper Atmospheric Research Program in the US with grants NNX07AE89G to MIT, NNX07AF09G and NNX07AE87G to SIO, by Defra and NOAA in the UK and by CSIRO and the Australian Government Bureau of Meteorology in Australia.

Edited by: N. M. Donahue

\section{References}

AFEAS, Alternative Fluorocarbons Environmental Acceptability Study, Production, Sales and Atmospheric Emissions of Fluorocarbons through 2003, Arlington, VA, www.afeas.org, 2005.

Bartos S., Beu, L. S., Burton, C. S., Fraust, C. L., Illuzzi, F., Mocella, M. T., and Raoux, S.: IPCC Guidelines for National Greenhouse Gas Inventories, Volume 3, Industrial Processes, Chapter 6, Electronics Industry, available online at: www.ipcc-nggip.iges.or.jp/public/2006gl/pdf/3 Volume3/V3_6_Ch6_Electronics_Industry.pdf, 2006.

Branscome, M. and Irving, W. N.: HFC-23 emissions from HCFC22 production, in Good Practice Guidance and Uncertainty Management in National Greenhouse Gas Inventories, Background paper prepared for the IPCC/OECD/IEA Programme on National Greenhouse Gas Inventories, Washington, available online at: www.ipcc-nggip.iges.or.jp/public/gp/bgp/3_8_HFC-23_ HCFC-22_Production.pdf, 1999.

Chen, Y.-H. and Prinn, R. G.: Estimation of atmospheric methane emissions between 1996 and 2001 using a three-dimensional global chemical transport model, J. Geophys. Res., 111, D10307, doi:10.1029/2005JD006058, 2006.

Clean Development Mechanism (CDM) Executive Board, Approved baseline methodology AM0001, Incineration of HFC 23 Waste Streams, version 1, available online at: http://cdm.unfccc. int/UserManagement/FileStorage/AM0001_v1.pdf, 2003.

Clerbaux, C., Cunnold, D. M., Anderson, J., Engel, A., Fraser, P. J., Mahieu, E., Manning, A., Miller, J., Montzka, S. A., Nassar, R., Prinn, R., Reimann, S., Rinsland, C. P., Simmonds, P., Verdonik, D., Weiss, R., Wuebbles, D., and Yokouchi, Y.: Chapter 1 Longlived Compounds, in Scientific Assessment of Ozone Depletion: 2006, World Meteorological Organization (WMO), Global Ozone Research and Monitoring Project, Report No. 50, available online at: http://ozone.unep.org/Assessment_Panels/SAP/ Scientific_Assessment_2006/index.asp, 2007.

Culberston, J. A., Prins, J. M., Grimsrud, E. P., Rasmussen, R. A., Khalil, M. A. K., and Shearer, M. J.: Observed trends in $\mathrm{CF}_{3}$-containing compounds in background air at Cape Meares, Oregon, Point Barrow, Alaska, and Palmer Station, Antarctica, Chemosphere, 55, 1109-1119, 2004.

Cunnold, D. M., Prinn, R. G., Rasmussen, R. A., Simmonds, P. G., Alyea, F. N., Cardelino, C. A., Crawford, A. J., Fraser, P. J., and Rosen, R. D.: The Atmospheric Lifetime Experiment 3. Lifetime 
Methodology and Application to Three Years of $\mathrm{CFCl}_{3}$ Data, J. Geophys. Res., 88, C13, 8379-8400, 1983.

Cunnold, D. M., Fraser, P. J., Weiss, R. F., Prinn, R. G., Simmonds, P. G., Miller, B. R., Alyea, F. N., and Crawford, A. J.: Global trends and annual releases of $\mathrm{CCl}_{3} \mathrm{~F}$ and $\mathrm{CCl}_{2} \mathrm{~F}_{2}$ estimated from ALE/GAGE and other measurements from July 1978 to June 1991, J. Geophys. Res., 99(D1), 1107-1126, 1994.

Daniel, J. S. and Velders, G. J. M. (lead authors), Douglas, A. R., Forster, P. M. D., Hauglustaine, D. A., Isaksen, I. S. A., Kuijpers, L. J. M., McCulloch, A., and Wallington, T. J.: Halocarbon scenarios, ozone depletion potentials, and global warming potentials. In: Scientific Assessment of Ozone Depletion: 2006, Global Ozone Research and Monitoring Project report no. 50. World Meteorological Organization, Geneva, Switzerland, 8.18.39, 2007.

DuPont, DuPont ${ }^{T M}$ Suva ${ }^{\circledR}$ refrigerants, Using HFC-23 for very low temperature (VLT) refrigeration, Technical Bulletin ART21, available online at: http://www2.dupont.com/Refrigerants/ en_US/assets/downloads/h53011_Freon23_for_vlt.pdf, 2004.

Earth System Research Laboratory/Physical Sciences Division (ESRL/PSD), Multivariate ENSO Index, available online at: http://www.esrl.noaa.gov/psd/enso/enso.mei_index.html, 2010.

Forster, P., Ramaswamy, V., Artaxo, P., Berntsen, T., Betts, R., Fahey, D. W., Haywood, J., Lean, J., Lowe, D. C., Myhre, G., Nganga, J., Prinn, R., Raga, G., Schulz, M., and Van Dorland, R.: Changes in Atmospheric Constituents and in Radiative Forcing. In: Climate Change 2007: The Physical Science Basis. Contribution of Working Group I to the Fourth Assessment Report of the Intergovernmental Panel on Climate Change, edited by: Solomon, S., Qin, D., Manning, M., Chen, Z., Marquis, M., Averyt, K. B., Tignor, M., and Miller, H. L., Cambridge University Press, Cambridge,UK and New York, NY, USA, 2007.

Gelb, A.: Applied Optimal Estimation, MIT Press, Cambridge, Massachusetts, USA, 1st ed., 370 pp., 1974.

Intergovernmental Panel on Climate Change (IPCC), Second Assessment Report, Climate Change 1995, The Science of Climate Change, edited by J. T. Houghton, L. G. Meira Filho, B. A. Callander, N. Harris, A. Kattenberg and K. Maskell, available online at: www.ipcc.ch/publications_and_data/publications_and_ data_reports.htm\#1, 1996.

Intergovernmental Panel on Climate Change (IPCC), Special Report on Safeguarding the Ozone Layer and the Global Climate System: Issues Related to Hydrofluorocarbons and Perfluorocarbons, edited by: Metz, B., Kuijpers, L., Solomon, S., Andersen, S. O., Davidson, O., Pons, J., de Jager, D., Kestin, T., Manning, M., and Meyer, L., Cambridge Univ. Press, Cambridge, UK, 478 pp., 2005.

Intergovernmental Panel on Climate Change (IPCC), Guidelines for National Greenhouse Gas Inventories, Volume 1, General Guidance and Reporting, available online at: http://www.ipcc-nggip. iges.or.jp/public/2006gl/vol1.html, 2006.

Langenfelds, R. L., Fraser, P. J., Francey, R. J., Steele, L. P., Porter, L. W., and Allison, C. E.: The Cape Grim air archive: The first seventeen years, 1978-1995, in Baseline Atmospheric Program (Australia) 1994-95, edited by: Francey, R. J., Dick, A. L., and Derek, N., Bureau of Meteorology, Commonwealth Scientific and Industrial Research Organisation, Melbourne, Victoria, Australia, 53-70, 1996.

McCulloch, A.: Incineration of HFC-23 Waste Streams for Abate- ment of Emissions from HCFC-22 Production: A Review of Scientific, Technical and Economic Aspects, commissioned by the UNFCCC secretariat to facilitate the work of the Methodologies Panel of the CDM Executive Board, available online at: http: //cdm.unfccc.int/methodologies/Background_240305.pdf, 2004.

McCulloch, A. and Lindley, A. A.: Global emissions of HFC-23 estimated to year 2015, Atmos. Environ., 41, 1560-1566, 2007.

Miller, B. R.: Abundances and Trends of Atmospheric Chlorodifluoromethane and Bromomethane, Ph.D. Thesis, Scripps Institution of Oceanography, University of California, San Diego, USA, 1998.

Miller, B. R., Weiss, R. F., Salameh, P. K., Tanhua, T., Greally, B. R., Mühle, J., and Simmonds, P. G.: Medusa: A Sample Preconcentration and GC/MSD Detector System for in Situ Measurements of Atmospheric Trace Halocarbons, Hydrocarbons and Sulfur Compounds, Anal. Chem., 80, 1536-1545, 2008.

Montzka, S. A., Hall, B. D., and Elkins, J. W.: Accelerated increases observed for hydrochlorofluorocarbons since 2004 in the global atmosphere, Geophys. Res. Lett., 36, L03804, doi:10.1029/2008GL036475, 2009.

Montzka, S. A., Kuijpers, L., Battle, M. O., Aydin, M., Verhulst, K. R., Saltzman, E. S., and Fahey, D. W.: Recent increases in global HFC-23 emissions, Geophys. Res. Lett., 37, L02808, doi:10.1029/2009GL041195, 2010.

Naik, V., Jain, A. K., Patten, K. O., and Wuebbles, D. J.: Consistent sets of atmospheric lifetimes and radiative forcings on climate for CFC replacements: HCFCs and HFCs, J. Geophys. Res., 105(D5), 6903-6914, 2000.

Oram, D. E., Sturges, W. T., Penkett, S. A., McCulloch, A., and Fraser, P. J.: Growth of fluoroform $\left(\mathrm{CHF}_{3}, \mathrm{HFC}-23\right)$ in the background atmosphere, Geophys. Res. Lett., 25(1), 35-38, 1998.

Prinn, R. G.: Measurement equation for trace chemicals in fluids and solution of its inverse, edited by Kasibhatla, P., Heimann, M., Rayner, P., Mahowald, N., Prinn, R. G., and Hartley, D. E.: Inverse Methods in Global Biogeochemical Cycles. American Geophysical Union, Washington DC, USA, 2000.

Prinn, R. G., Weiss, R. F., Fraser, P. J., Simmonds, P. G., Cunnold, D. M., Alyea, F. N., O’Doherty, S., Salameh, P., Miller, B. R., Huang, J., Wang, R. H. J., Hartley, D. E., Harth, C., Steele, L. P., Sturrock, G., Midgley, P. M., and McCulloch, A.: A history of chemically and radiatively important gases in air deduced from ALE/GAGE/AGAGE, J. Geophys. Res., 105, 17751-17792, 2000.

Risoe National Laboratory, UNEP Risoe CDM/JI Pipeline Analysis and Database, UNEP Risoe Centre, Denmark, available online at: http://cdmpipeline.org, 2010.

Rotherham, D.: Greenhouse Gas Emission Reduction Verification Audit for Dupont's Louisville Works Freon®22 Plant, Final Report, ICF Consulting, Toronto, Canada, available online at: http://cdm.unfccc.int/public_inputs/inputam0001/Letter_ Dupont_Annex2_03June04.pdf, 2004.

Sander, S. P., Friedl, R. R., Golden, D. M., Kurylo, M. J., Moortgat, G. K., Keller-Rudek, H., Wine, P. H., Ravishankara, A R., Kolb, C. E., Molina, M. J., Finlayson-Pitts, B. J., Huie, R. E., and Orkin, V. L.: Chemical kinetics and photochemical data for use in atmospheric studies evaluation number $15, \mathrm{Na}-$ tional Aeronautics and Space Administration, available online at: http://jpldataeval.jpl.nasa.gov/download.html, 2006.

United Nations Environment Programme (UNEP), Handbook for 
the International Treaties for the Protection of the Ozone Layer, 4th ed., Ozone Secretariat, Nairobi, 1996.

UNEP/TEAP: Task Force on Emissions Discrepancies Report, United Nations Environment Programme/Technology and Economic Assessment Panel, available online at: http://ozone.unep. org/teap/Reports/TEAP_Reports/TEAP-Discrepancy-report.pdf, 2006.

UNEP, Report of the 9th Meeting of the Parties to the Montreal Protocol on Substances that Deplete the Ozone Layer, UNEP/OzL. Pro. 19/7 (United Nations Environment Programme, Nairobi, Kenya), 2007.

UNEP Production and Feedstock Production data for HCFC-22, 1989-2008, as reported under Article 7 of the Montreal Protocol, UNEP Nairobi, March 2010.
UNFCCC: data in the Common Reporting Format, available online at: http://unfccc.int/di/DetailedByParty.do, 2010.

World Bank, Montreal Protocol (MP) Projects in China, available online at: http://web.worldbank.org/WBSITE/EXTERNAL/ COUNTRIES/EASTASIAPACIFICEXT/CHINAEXTN/

0, contentMDK:20585170 pagePK:1497618 piPK:

217854 theSitePK:318950,00.html, 2009.

Yokouchi, Y., Taguchi, S., Saito, T., Tohjima, Y., Tanimoto, H., and Mukai, H.: High frequency measurements of HFCs at a remote site in east Asia and their implications for Chinese emissions, Geophys. Res. Lett., 33, L21814, doi:10.1029/2006GL026403, 2006. 